\title{
AVALIAÇÃO DA APRENDIZAGEM PROFISSIONAL NO ESTÁGIO SUPERVISIONADO: ESTUDO EXPLORATÓRIO NA EDUCAÇÃO INFANTIL
}

SARA BARROS ARAÚJO ANA PEREIRA ANTUNES

\section{RESUMO}

0 presente estudo visa analisar processos de avaliação da aprendizagem profissional na formação prática, considerando o perfil específico de desempenho docente na educação infantil. Trata-se de um estudo exploratório em que participaram estudantes que frequentaram a componente de estágio de um mestrado de natureza profissionalizante em contexto português. Os dados foram recolhidos através de um instrumento de avaliação composto por 25 dimensões organizadas em quatro domínios (Observação, Planificação, Ação e Reflexão), aplicado em dois momentos: avaliação reguladora e avaliação final. Os resultados evidenciaram evolução positiva e estatisticamente significativaem21 das25dimensõesanalisadas, entreosdoismomentosde avaliação. Os dados permitem retirar ilações acerca de percursos de aprendizagem de competências profissionais e das potencialidades de uma abordagem autêntica e coparticipada na avaliação da formação prática e na compreensão endógena dos processos formativos.

\footnotetext{
PALAVRAS-CHAVE AVALIAÇÃo dA APRENDIZAGEM • DESENVOLVIMENTO PROFISSIONAL • ESTÁGIO SUPERVISIONADO • EDUCAÇÃO INFANTIL.
} 


\title{
EVALUACIÓN DEL APRENDIZAJE PROFESIONAL EN EL PRÁCTICUM SUPERVISADO: ESTUDIO EXPLORATORIO EN LA EDUCACIÓN INFANTIL
}

RESUMEN

El presente estudio tiene el propósito de analizar procesos de evaluación del aprendizaje profesional en la formación práctica, considerando el perfil específico de desempeño docente en la educación infantil. Se trata de un estudio exploratorio en el que participaron estudiantes que frecuentaron el prácticum de una maestría de formación profesional en contexto portugués. Los datos se recogieron a través de un instrumento de evaluación compuesto por 25 dimensiones organizadas en cuatro dominios (Observación, Planificación, Acción y Reflexión), aplicado en dos momentos: evaluación reguladora y evaluación final. Los resultados pusieron de manifiesto una evolución positiva y estadísticamente significativa en 21 de las 25 dimensiones analizadas, entre los dos momentos de evaluación. Los datos permiten retirar ilaciones acerca de recorridos de aprendizaje de competencias profesionales y de las potencialidades de un abordaje auténtico con coparticipación en la evaluación de la formación práctica y en la comprensión endógena de los procesos formativos.

PALABRAS CLAVE EVALUACIÓN DEL APRENDIZAJE • DESARROLLO PROFESIONAL • PRÁCTICUM SUPERVISADO・EDUCACIÓN INFANTIL.

\section{ASSESSMENT OF PROFESSIONAL LEARNING IN SUPERVISED PRACTICUM: EXPLORATORY STUDY IN EARLY CHILDHOOD EDUCATION}

\begin{abstract}
This study aims to analyze professional learning assessment procedures considering the specific teaching performance profile in early childhood education. A cohort of Portuguese students involved in a practicum in early childhood education, at a master level, participated in this exploratory study. Data were collected using an assessment instrument composed of 25 dimensions organized in four domains (Observation, Planning, Action and Reflection), applied at two different instances: regulatory assessment and final assessment. The results showed a statistically significant and positive evolution in 21 of the 25 dimensions examined, between the two instances of assessment. Data allow conclusions to be drawn regarding the learning of professional skills, and the potentialities of an authentic and co-participative approach in the assessment of practical training and in the endogenous understanding of training processes.
\end{abstract}

KEYWORDS LEARNING ASSESSMENT • PROFESSIONAL DEVELOPMENT • SUPERVISED PRACTICUM • EARLY CHILDHOOD EDUCATION. 


\section{INTRODUÇÃO}

O Processo de Bolonha trouxe, em Portugal, mudanças significativas no regime jurídico de habilitação para a docência na educação infantil, regulamentada, numa primeira fase, através do Decreto-lei n. 43/2007, de 22 de fevereiro (PORTUGAL, 2007), entretanto substituído pelo Decreto-lei n. 79/2014, de 14 de maio (PORTUGAL, 2014). Dentre as várias mudanças registadas, é de salientar que a formação para docência na educação infantil passou a ser realizada num modelo sequencial de dois ciclos de estudos: uma licenciatura de três anos em educação básica, destinada a assegurar a formação de base na área da docência, e um mestrado profissionalizante destinado a aprofundar e reforçar a formação académica, particularmente nas didáticas específicas e na prática supervisionada. Dentre as cinco componentes de for-

1 Os ciclos de estudos que visam a habilitação profissional para a docência integram as seguintes componentes de formação: (i) área de docência; (ii) área educacional geral; (iii) didáticas específicas; (iv) área social, cultural e ética; ( $v$ ) iniciação à prática profissional (PORTUGAL, 2014, art. 7ํ) mação ${ }^{1}$ previstas para os ciclos de estudos de habilitação profissional para a docência, é de assinalar a "Iniciação à prática profissional”, que inclui a prática supervisionada na sala de atividades ou sala de aula. Esta componente era concebida, no articulado do Decreto-lei n. 43/2007, 
[...] numa perspectiva de desenvolvimento profissional dos formandos visando o desempenho como futuros docentes e promovendo uma postura crítica e reflexiva em relação aos desafios, processos e desempenhos do quotidiano profissional. (PORTUGAL, 2007, art. 14)

No Decreto-lei n. 79/2014, este articulado sofre alterações, passando a elencar, no art. $11^{\circ}$, dentre outros, os seguintes princípios de organização da Iniciação à prática profissional:

[...] d) É concebida numa perspetiva de formação para a articulação entre o conhecimento e a forma de o transmitir visando a aprendizagem; e) É concebida numa perspetiva de desenvolvimento profissional dos formandos e promove nestes uma atitude orientada para a permanente melhoria da aprendizagem dos seus alunos. (PORTUGAL, 2014, art. 11)

Apesar de inflexões relevantes na forma de concetualizar esta componente de formação, nomeadamente no nexo entre educação/ensino e aprendizagem introduzido na versão revista do regime jurídico, bem como na retração ao nível da assunção de uma postura crítica e reflexiva, manteve-se a tónica numa perspetiva de desenvolvimento profissional associado a esta componente formativa.

O presente estudo centra-se na formação prática de educadores/as de educação infantil e, muito particularmente, no estágio desenvolvido no âmbito de um mestrado profissionalizante, reconhecendo-o como espaço e tempo de relevância central na formação destes docentes. Gomes (2013) considera o estágio uma oportunidade de ação profissional qualificada, de diálogo com o mundo do trabalho através de sua análise crítica, articulando dialeticamente o saber teórico e o saber prático (desenvolvimento da práxis). Em convergência surgem as ideias de Calderano (2012, p. 270), que afirma:

[...] o estágio curricular não se reduz à prática, no sentido operacional. $\bigcirc$ estágio precisa se constituir em uma oportunidade de estreitar as relações entre reflexões teórico-práticas, visualização ampliada do processo educacional, descoberta e delineamento de desafios encontrados para, 
numa perspectiva de síntese, atingir a construção conjun-

ta de alternativas pedagógicas para os problemas identificados.

Por seu turno, Dayan (2008) adianta que o estágio, no âmbito dos programas de formação de educadores/as de infância, envolve os estudantes num processo desenvolvimental de observação e experimentação de práticas de trabalho com crianças, bem como de aprendizagem de competências, conhecimentos, filosofias e atitudes em contextos educativos.

Pela sua relevância no percurso formativo dos estudantes, reconhece-se a necessidade de processos de avaliação que, numa lógica de monitorização e melhoria das práticas, preservem a natureza complexa da atividade docente enquanto atividade intelectual, técnica, moral e relacional (FORMOSINHO, 2002), sejam abertos a um perfil polifacetado de competências (FORMOSINHO; MACHADO, 2010) e facilitadores da construção de conhecimento profissional de tipo praxeológico (FORMOSINHO; MACHADO, 2009). Formosinho (2009) considera que as formas de avaliar e regular as aprendizagens fazem parte da dimensão manifesta de um currículo de processos na formação de docentes, constituindo práticas particularmente marcantes de um currículo oculto e não problematizado. No âmbito mais circunscrito da formação de profissionais da educação infantil, Jensen (2015) adianta que a identificação de modos adequados para avaliar a aprendizagem dos estudantes nos contextos da prática constitui um desafio aos programas de formação. No presente trabalho, assume-se que os instrumentos intervenientes e procedimentos implicados na avaliação do desempenho dos estagiários deverão ser alvo de análise, não só pelo impacto que poderão ter nos percursos de aprendizagem profissional, mas também pela influência na compreensão dos processos formativos.

\section{AVALIAÇÃO DE DESEMPENHO NA FORMAÇÃO PRÁTICA INICIAL}

De acordo com Caughlan e Jiang (2014), a avaliação do desempenho especifica o que os docentes ou candidatos a docentes 
devem saber e saber fazer em contextos reais de ensino. Esta avaliação tem vindo a ser associada à melhoria das práticas de ensino dos futuros docentes (CAUGHLAN; JIANG, 2014) e nos casos em que se reconhece sua natureza formativa como influente nos seus processos de aprendizagem e reflexividade (WEI; PECHEONE, 2010).

Darling-Hammond (2001) considera que a avaliação de desempenho de futuros docentes deve ser baseada em visões complexas e holísticas do ensino e em padrões de desempenho profissional validados, numa linha de avaliação autêntica sensível aos contextos, longitudinal e individualizada. A autora considera que uma avaliação desta natureza oferece medidas mais válidas do conhecimento e competências dos professores que os testes tradicionais (DARLING-HAMMOND, 2006; DARLING-HAMMOND; NEWTON; WEI, 2013). Na ótica de Darling-Hammong e Snyder (2000), sob o escopo da avaliação autêntica incluem-se oportunidades para o desenvolvimento e análise do pensamento e ações dos professores em situações baseadas na experiência e orientadas para a resolução de problemas. Os autores salientam que esta abordagem autêntica à avaliação dos futuros docentes os apoia a deslocarem-se de generalizações acerca da prática para instâncias de aprendizagem aparentemente mais idiossincráticas, contextualizadas e responsivas à multidimensionalidade dos problemas e possibilidades de cada aluno. Paralelamente, uma abordagem autêntica à avaliação poderá inspirar alterações nos programas de formação, pelo providenciar de informação relevante acerca das características dos candidatos a docentes, aspeto crítico no âmbito de uma agenda de avaliação com preocupações dirigidas, em paralelo à documentação e melhoria da formação docente (DARLING-HAMMOND, 2006).

$\mathrm{Na}$ revisão da literatura realizada por Alves e Cabral (2015), a avaliação assim concebida enquadra-se numa quarta geração da avaliação pedagógica que adota uma perspetiva construtivista, participativa e negocial no âmbito do processo avaliativo. Especificamente no que concerne ao perfilhar de uma abordagem participativa, Wiggins (1989) salienta que a avaliação torna-se mais rigorosa, justa e equitativa quando envolve a opinião e o diálogo, integrando o 
input e feedback daquele que está a ser avaliado. Assim, a responsividade aos contextos estende-se à responsividade aos indivíduos, reconhecendo-se a justiça e o rigor de práticas democráticas concretizadas através do exercício de deliberação coletiva (MOSS; DALHBERG, 2008). Caughlan e Jiang (2014) propõem o conceito de "profissionalismo agêntico" para se referirem à importância de a escolha e utilização de instrumentos de avaliação do desempenho considerarem aspetos como o posicionamento, poder e agência dos estudantes ou a criação de oportunidades de tomada de decisão. De facto, os autores salientam que estes instrumentos não são neutros, mas refletem os valores dos programas que os utilizam; argumentam, ainda, que os programas deverão manter vigilância relativamente à consistência entre a teoria de aprendizagem preconizada e praticada e a teoria de avaliação, uma vez que ambas se encontram, frequentemente, em dissonância.

Concentrada na formação de educadores de infância, Dayan (2008) defende uma abordagem humanístico-democrática no âmbito dos processos supervisivos, em que estudantes, orientadores cooperantes e supervisores institucionais se possam envolver em parcerias e processos democráticos de deliberação e discussão. São corolários desta abordagem o desenvolvimento da autonomia do estagiário e a promoção do sentido de responsabilidade pela sua aprendizagem e pelo seu crescimento profissional. Numa linha semelhante, Dalrymple, Kemp e Smith (2014) sustentam a relevância de um modelo triádico em que o estudante, o facilitador do contexto de trabalho e o tutor da universidade detêm papéis interdependentes e harmonizados. Os autores referem que as configurações mais eficazes do ponto de vista da aprendizagem em contextos de trabalho (como é o caso dos estágios profissionalizantes) envolvem a confluência destes três atores no processo de aprendizagem e a criação de oportunidades, entre outras, para que os estudantes se tornem coprodutores de conhecimento. Reconhecem, ainda, o papel dos supervisores no âmbito daquilo que designam facilitação responsiva, caracterizada centralmente pelo encorajamento à identificação e avaliação crítica pelos 
estudantes das suas compreensões e práticas. Por seu turno, Calderano (2013, p. 48) aponta, no seu extenso estudo acerca do estágio curricular na formação inicial e continuada, as possibilidades de uma "conceção marcada pela organicidade entre escola e universidade, entre teoria e prática, entre formação e trabalho docente". A autora salienta a relevância da conceção e exercício de uma docência compartilhada no âmbito dos estágios, em que os professores da universidade e da escola se envolvem num trabalho colegial (CALDERANO, 2012, 2013). Nesta conceção, o estatuto epistemológico do estagiário é revisto, cabendo-lhe uma participação ativa no processo formativo e, por inerência, na própria avaliação (CALDERANO, 2013).

O presente estudo inscreve-se numa avaliação autêntica e coparticipada do desempenho na formação prática inicial de educadores infantis. Tem como objetivo analisar a evolução de estudantes de um mestrado profissionalizante ao nível de competências profissionais relevantes no que respeita ao perfil específico de desempenho docente, com base numa avaliação participada e individualizada. Visa, igualmente, numa lógica de monitorização interna, servir de base à compreensão endógena dos processos formativos, procurando sua permanente adequação a necessidades identificadas (por exemplo, ao nível dos processos supervisivos).

\section{MÉTODO}

\section{PARTICIPANTES}

Participaram no estudo 41 estudantes (40 mulheres e um homem) que frequentaram o estágio de um mestrado profissionalizante em educação infantil numa instituição de ensino superior do norte de Portugal, nos anos letivos de 2012/2013 (19 estudantes, 18 mulheres e um homem) e 2013/2014 (22 estudantes mulheres).

\section{INSTRUMENTO}

Utilizou-se a Grelha de Avaliação sobre os Processos de Desenvolvimento na Prática Pedagógica Supervisionada (GAPD_PPS). A utilização desta grelha, de base observacional 
e reflexiva, tem a dupla função de servir à avaliação reguladora e avaliação final do processo de desenvolvimento de conhecimentos e competências profissionais. Sua construção tomou em consideração o perfil específico de desempenho profissional do educador de infância (PORTUGAL, 2001), os princípios orientadores da formação na prática pedagógica da instituição formadora e, ainda, referentes teóricos relevantes no âmbito da formação, designadamente os modelos curriculares para a educação de infância (OLIVEIRA-FORMOSINHO, 2007). A grelha encontra-se organizada em quatro domínios que integram dimensões centrais do desempenho docente: (i) Observação (cinco dimensões); (ii) Planificação (seis dimensões); (iii) Ação (nove dimensões); e (iv) Reflexão (cinco dimensões), como se pode verificar no Quadro 1.

QUADRO 1 - Domínios e dimensões da GAPD_PPS

\begin{tabular}{|c|c|c|c|}
\hline \multicolumn{4}{|c|}{ DOMÍNIOS E DIMENSÕES DA GAPD_PPS } \\
\hline OBSERVAÇÃO & PLANIFICAÇÃO & AÇÃO & REFLEXÃO \\
\hline $\begin{array}{l}\text { D1: Conhecimentos teóricos } \\
\text { e de enquadramento legal }\end{array}$ & $\begin{array}{l}\text { D6: Conhecimento do } \\
\text { currículo e dos conteúdos }\end{array}$ & $\begin{array}{l}\text { D12: Organização do espaço } \\
\text { e materiais }\end{array}$ & $\begin{array}{l}\text { D21: Reflexão sobre, na e } \\
\text { para a ação }\end{array}$ \\
\hline $\begin{array}{l}\text { D2: Observação da criança e } \\
\text { dos grupos }\end{array}$ & $\begin{array}{l}\text { D7: Coerência com o projeto } \\
\text { curricular do grupo }\end{array}$ & D13: Organização do tempo & $\begin{array}{l}\text { D22: Mobilização de } \\
\text { referentes teóricos e legais }\end{array}$ \\
\hline D3: Práticas de registo & D8: Estratégias e recursos & D14: Interações pedagógicas & $\begin{array}{l}\text { D23: Postura indagadora e } \\
\text { crítica }\end{array}$ \\
\hline $\begin{array}{l}\text { D4: Recolha de informação } \\
\text { sobre os contextos }\end{array}$ & $\begin{array}{l}\text { D9: Articulação, objetivos, } \\
\text { estratégias e avaliação }\end{array}$ & $\begin{array}{l}\text { D15: Estratégias } \\
\text { diferenciadas }\end{array}$ & $\begin{array}{l}\text { D24: Articulação de diversos } \\
\text { pontos de vista, valores, } \\
\text { saberes e crenças }\end{array}$ \\
\hline \multirow[t]{5}{*}{$\begin{array}{l}\text { D5: Auto e hétero- } \\
\text { observação }\end{array}$} & $\begin{array}{l}\text { D10: Integração de } \\
\text { propostas das crianças e } \\
\text { situações imprevistas }\end{array}$ & $\begin{array}{l}\text { D16: Envolvimento das } \\
\text { crianças em projetos }\end{array}$ & $\begin{array}{l}\text { D25: Avaliação crítica acerca } \\
\text { do seu papel e funções }\end{array}$ \\
\hline & $\begin{array}{l}\text { D11: Natureza integradora e } \\
\text { diferenciação pedagógica }\end{array}$ & $\begin{array}{l}\text { D17: Integração de situações } \\
\text { de jogo espontâneo }\end{array}$ & \\
\hline & & $\begin{array}{l}\text { D18: Construção de } \\
\text { parcerias com família e } \\
\text { comunidade }\end{array}$ & \\
\hline & & $\begin{array}{l}\text { D19: Interações colaborativas } \\
\text { com equipas de sala e } \\
\text { centro educativo }\end{array}$ & \\
\hline & & $\begin{array}{l}\text { D20: Postura democrática, } \\
\text { ética e deontológica }\end{array}$ & \\
\hline
\end{tabular}

Fonte: Elaboração das autoras.

Nota: D: Dimensão. 


\section{PROCEDIMENTOS}

A GAPD_PPS foi utilizada em dois momentos do estágio: numa fase intermédia, com propósitos de monitorização do processo de aprendizagem profissional, e, no final do estágio, com objetivo de avaliação final, com consequências ao nível da avaliação sumativa. Num momento inicial, a GAPD_PPS foi apresentada às/aos estagiárias e orientadoras cooperantes (educadoras de infância que acompanham o estágio em contextos da prática), clarificando-se dúvidas relativamente às dimensões que a compõem. Posteriormente, sua utilização, em cada um dos momentos de avaliação, concretizou-se em três fases: (i) autoavaliação, compreendendo uma reflexão retrospetiva e prospetiva da/o estagiária/o acerca do seu desempenho em cada uma das dimensões; (ii) reunião reflexiva entre as/os estagiárias/os (o estágio é realizado em pares de formação) e respetiva orientadora cooperante centrada em processos de auto e heteroavaliação dos desempenhos; (iii) reunião entre as/os estagiárias/os, orientadora cooperante e supervisor/a institucional realizada nos contextos de estágio, visando a análise colaborativa e coparticipada dos processos de aprendizagem profissional.

No caso da avaliação reguladora, da reunião de auto e heteroavaliação e reflexão resultou um conjunto de intenções e prioridades ao nível da melhoria do desempenho docente em cada uma das dimensões, explicitadas no espaço da grelha dedicado a “observações”. Destas reuniões resultou também a atribuição consensualizada de um nível de desempenho em cada uma das dimensões, numa escala com a seguinte correspondência: A: excelente; B: muito bom; C: bom; D: suficiente; $\mathrm{E}$ : insuficiente (sendo que, em alguns dos casos, recorreu-se a uma valoração intermédia como, por exemplo, B+: muito bom, mas ainda não ao nível do excelente). Esta atribuição pretende a trasladação dos resultados de um processo reflexivo para uma abordagem tendentemente mais quantitativa, facilitadora da leitura da análise evolutiva da/o estudante.

No caso da reunião de avaliação final, esta atribuição associa-se à necessidade de classificação inerente à avaliação de tipo sumativo para a qual concorre este momento reflexivo entre formadoras/es e estagiárias/os. O presente estudo faz uso destas atribuições para analisar a evolução das/os 
estudantes nas dimensões da GAPD_PPS. Mais concretamente, procedeu-se a uma equiparação, para efeitos deste estudo, dos valores qualitativos a valores quantitativos, a saber: às classificações de A, B, C, D e E fez-se a correspondência das classificações 5, 4, 3, 2 e 1, respetivamente.

\section{RESULTADOS}

Nesta secção apresentam-se os resultados obtidos através da utilização da GAPD_PPS em cada um dos seus domínios (Observação, Planificação, Ação e Reflexão). Dado o número de participantes no estudo não ser muito alargado (41 sujeitos) e a escala de medida das variáveis em estudo poder ser considerada ordinal, optou-se por uma análise estatística para comparação de resultados através de testes não paramétricos (MARTINS, 2011), mais concretamente o teste não paramétrico de Wilcoxon (signed-rank) (FIELD, 2009).

Ao iniciar-se a apresentação dos resultados pelo domínio Observação, a consulta à Tabela 1 permite constatar diferenças estatisticamente significativas em todas as dimensões avaliadas neste domínio $(p<0,05)$, traduzindo uma diferenciação dos resultados dos alunos nos dois momentos de avaliação, nos quais se regista uma melhoria dos resultados no momento de avaliação final.

TABELA 1 - Apresentação dos resultados obtidos na avaliação reguladora e na avaliação final no que se refere às dimensões do domínio Observação

\begin{tabular}{|c|c|c|c|c|c|c|c|c|c|}
\hline \multirow{2}{*}{ DIMENSÃO } & \multirow{2}{*}{ MOMENTO } & \multirow{2}{*}{$\mathrm{N}$} & \multirow{2}{*}{ MEDIANA } & \multirow{2}{*}{ MÉDIA } & \multirow{2}{*}{$\begin{array}{l}\text { DESVIO- } \\
\text {-PADRÃO }\end{array}$} & \multirow{2}{*}{ MÍN. } & \multirow{2}{*}{ MÁX. } & \multicolumn{2}{|c|}{$\begin{array}{l}\text { TESTE DE } \\
\text { WILCOXON }\end{array}$} \\
\hline & & & & & & & & $z$ & $p$ \\
\hline \multirow{2}{*}{1} & 1 & 41 & 2,5 & 2,7 & 0,69 & 1 & 4,5 & \multirow{2}{*}{$-4,371$} & \multirow{2}{*}{0,000} \\
\hline & 11 & 41 & 3 & 3,4 & 0,81 & 1 & 4,5 & & \\
\hline \multirow{2}{*}{2} & 1 & 41 & 3 & 3,1 & 0,52 & 2 & 4 & \multirow{2}{*}{$-3,452$} & \multirow{2}{*}{0,00} \\
\hline & 11 & 41 & 3,5 & 3,4 & 0,67 & 2 & 4 & & \\
\hline \multirow{2}{*}{3} & 1 & 41 & 3 & 2,8 & 0,81 & 1 & 4 & \multirow{2}{*}{$-3,369$} & \multirow{2}{*}{0,001} \\
\hline & 11 & 41 & 3 & 3,2 & 0,72 & 1 & 4 & & \\
\hline \multirow{2}{*}{4} & 1 & 41 & 3 & 3,1 & 0,61 & 2 & 4 & \multirow{2}{*}{$-3,147$} & \multirow{2}{*}{0,002} \\
\hline & 11 & 41 & 3,5 & 3,5 & 0,76 & 2 & 4,5 & & \\
\hline \multirow{2}{*}{5} & 1 & 41 & 3 & 2,9 & 0,53 & 1 & 4 & \multirow{2}{*}{$-3,257$} & \multirow{2}{*}{0,001} \\
\hline & 11 & 41 & 3 & 3,3 & 0,67 & 1 & 4 & & \\
\hline
\end{tabular}

Fonte: Elaboração das autoras.

Momento: I - Avaliação reguladora; II - Avaliação final. 
Em relação ao domínio Planificação, os resultados encontrados seguem a tendência registada previamente no domínio Observação, ou seja, assiste-se a uma melhoria estatisticamente significativa no desempenho dos alunos, favorável ao momento de avaliação final $(p<0,05)$, conforme se constata na Tabela 2.

TABELA 2 - Apresentação dos resultados obtidos na avaliação reguladora e na avaliação final no que se refere às dimensões do domínio Planificação

\begin{tabular}{|c|c|c|c|c|c|c|c|c|c|}
\hline \multirow{2}{*}{ DIMENSÃO } & \multirow{2}{*}{ MOMENTO } & \multirow{2}{*}{$\mathrm{N}$} & \multirow{2}{*}{ MEDIANA } & \multirow{2}{*}{ MÉDIA } & \multirow{2}{*}{$\begin{array}{l}\text { DESVIO- } \\
\text {-PADRÃO }\end{array}$} & \multirow{2}{*}{ MíN. } & \multirow{2}{*}{ MÁX. } & \multicolumn{2}{|c|}{$\begin{array}{l}\text { TESTE DE } \\
\text { WILCOXON }\end{array}$} \\
\hline & & & & & & & & Z & $p$ \\
\hline \multirow{2}{*}{6} & 1 & 41 & 3 & 3,0 & 0,61 & 2 & 4 & \multirow{2}{*}{$-3,507$} & \multirow{2}{*}{0,000} \\
\hline & 11 & 41 & 3,5 & 3,4 & 0,70 & 1 & 4,5 & & \\
\hline \multirow{2}{*}{7} & 1 & 41 & 3 & 3,3 & 0,55 & 2 & 4 & \multirow{2}{*}{$-3,139$} & \multirow{2}{*}{0,002} \\
\hline & 11 & 41 & 4 & 3,6 & 0,68 & 2 & 4,5 & & \\
\hline \multirow{2}{*}{8} & 1 & 41 & 3 & 3,0 & 0,55 & 2 & 4,5 & \multirow{2}{*}{$-4,036$} & \multirow{2}{*}{0,000} \\
\hline & $\|$ & 41 & 3,5 & 3,6 & 0,59 & 2 & 4,5 & & \\
\hline \multirow{2}{*}{9} & 1 & 41 & 3 & 2,9 & 0,61 & 1 & 4 & \multirow{2}{*}{$-3,821$} & \multirow{2}{*}{0,000} \\
\hline & ॥ & 41 & 3,5 & 3,6 & 0,74 & 1 & 4,5 & & \\
\hline \multirow{2}{*}{10} & 1 & 41 & 3 & 3,1 & 0,70 & 2 & 4 & \multirow{2}{*}{$-3,293$} & \multirow{2}{*}{0,001} \\
\hline & II & 41 & 4 & 3,5 & 0,82 & 1 & 4,5 & & \\
\hline \multirow{2}{*}{11} & I & 41 & 3 & 2,9 & 0,54 & 2 & 4,5 & \multirow{2}{*}{$-3,403$} & \multirow{2}{*}{0,001} \\
\hline & $\|$ & 41 & 3 & 3,4 & 0,52 & 2,5 & 4,5 & & \\
\hline
\end{tabular}

Fonte: Elaboração das autoras.

Momento: I - Avaliação reguladora; II - Avaliação final.

Uma análise mais detalhada da Tabela 2 permite verificar que na dimensão 6 , na avaliação final, houve uma queda no valor mínimo atribuído (desceu de 2 para 1), pelo que se decidiu proceder à análise individual dos sujeitos, procurando compreender este resultado, o que permitiu verificar que este se deve à descida de desempenho do sujeito 8. Também na dimensão 10, na avaliação final, regista-se a diminuição da classificação mínima (desceu de 2 para 1), sendo que esta se deve igualmente à descida de desempenho por parte do sujeito 8.

No que diz respeito ao domínio Ação, os resultados referentes às dimensões avaliadas são apresentados na Tabela 3 , em função do momento de avaliação, sendo que os alunos não parecem ter evoluído de forma estatisticamente significativa em todas as dimensões consideradas. 
TABELA 3 - Apresentação dos resultados obtidos na avaliação reguladora e na avaliação final no que se refere às dimensões do domínio Ação

\begin{tabular}{|c|c|c|c|c|c|c|c|c|c|}
\hline \multirow{2}{*}{ DIMENSÃO } & \multirow{2}{*}{ MOMENTO } & \multirow{2}{*}{$\mathrm{N}$} & \multirow{2}{*}{ MEDIANA } & \multirow{2}{*}{ MÉDIA } & \multirow{2}{*}{$\begin{array}{l}\text { DESVIO- } \\
\text {-PADRÃO }\end{array}$} & \multirow{2}{*}{ MÍN. } & \multirow{2}{*}{ MÁX. } & \multicolumn{2}{|c|}{$\begin{array}{l}\text { TESTE DE } \\
\text { WILCOXON }\end{array}$} \\
\hline & & & & & & & & Z & $p$ \\
\hline \multirow{2}{*}{12} & 1 & 41 & 3 & 2,8 & 0,66 & 2 & 4,5 & \multirow{2}{*}{$-4,280$} & \multirow{2}{*}{0,000} \\
\hline & 11 & 41 & 3,5 & 3,5 & 0,58 & 2 & 4,5 & & \\
\hline \multirow{2}{*}{13} & 1 & 41 & 3 & 3,1 & 0,71 & 1 & 4,5 & \multirow{2}{*}{$-1,923$} & \multirow{2}{*}{0,054} \\
\hline & 11 & 41 & 3,5 & 3,4 & 0,66 & 2 & 4,5 & & \\
\hline \multirow{2}{*}{14} & 1 & 41 & 3 & 3,1 & 0,75 & 1 & 4 & \multirow{2}{*}{$-3,131$} & \multirow{2}{*}{0,002} \\
\hline & 11 & 41 & 4 & 3,4 & 0,76 & 1 & 4,5 & & \\
\hline \multirow{2}{*}{15} & 1 & 41 & 3 & 3,0 & 0,54 & 1 & 4,5 & \multirow{2}{*}{$-4,127$} & \multirow{2}{*}{0,000} \\
\hline & $\|$ & 41 & 4 & 3,5 & 0,65 & 1,5 & 4,5 & & \\
\hline \multirow{2}{*}{16} & 1 & 27 & 3 & 2,7 & 0,87 & 1 & 4 & \multirow{2}{*}{$-3,488$} & \multirow{2}{*}{0,000} \\
\hline & 11 & 41 & 3,5 & 3,6 & 0,58 & 2,5 & 4,5 & & \\
\hline \multirow{2}{*}{17} & 1 & 41 & 3,5 & 3,4 & 0,71 & 1 & 4,5 & \multirow{2}{*}{$-1,503$} & \multirow{2}{*}{0,133} \\
\hline & 11 & 41 & 4 & 3,5 & 0,67 & 2 & 4,5 & & \\
\hline \multirow{2}{*}{18} & 1 & 40 & 2 & 2,4 & 0,92 & 1 & 5 & \multirow{2}{*}{$-4,686$} & \multirow{2}{*}{0,000} \\
\hline & 11 & 41 & 3 & 3,4 & 0,62 & 2 & 4,5 & & \\
\hline \multirow{2}{*}{19} & 1 & 41 & 3 & 3,3 & 0,73 & 1 & 5 & \multirow{2}{*}{$-2,628$} & \multirow{2}{*}{0,009} \\
\hline & 11 & 41 & 4 & 3,6 & 0,65 & 2 & 4,5 & & \\
\hline \multirow{2}{*}{20} & 1 & 41 & 4,5 & 4,3 & 0,72 & 3 & 5 & 00250 & ع 70 \\
\hline & $\|$ & 41 & 5 & 4,3 & 0,79 & 3 & 5 & $-0,230$ & 0,190 \\
\hline
\end{tabular}

Fonte: Elaboração das autoras.

Momento: I - Avaliação reguladora; II - Avaliação final.

A análise da Tabela 3 permite constatar que, entre a avaliação reguladora e a avaliação final, registam-se dimensões em que ocorreu subida no valor das médias, sendo que a diferença na distribuição de resultados revela-se estatisticamente significativa $(p<0,05)$ para a dimensão 12 . A dimensão 13 regista apenas uma diferenciação marginalmente significativa $(p=0,054)$. No entanto, para a dimensão 17 e para a dimensão 20 não se registam diferenças estatisticamente significativas entre os dois momentos de avaliação $(p>0,05)$.

Verifica-se, ainda, que nas dimensões 18 e 19 houve diminuição do valor máximo atribuído (desceu de 5 para 4,5) na avaliação final, pelo que se decidiu analisar os desempenhos individuais dos alunos, constatando-se que o aluno 17, que teve, na avaliação reguladora, a classificação de 5 , desceu para 3 na avaliação final, enquanto o aluno 34, que na dimensão 19 teve, na avaliação reguladora, a classificação de 5, desceu para 3,5 na avaliação final. 
O domínio Reflexão, o último em análise (Tabela 4), caracteriza-se pela diferenciação estatisticamente significativa dos resultados obtidos nas duas avaliações $(p<0,05)$, apontando para resultados superiores na avaliação final em quatro das dimensões avaliadas, ou seja, na dimensão 21 , na dimensão 22 , na dimensão 23 e na dimensão 25. Todavia, para a dimensão 24 não se registam diferenças estatisticamente significativas entre os dois momentos de avaliação $(p>0,05)$.

TABELA 4 - Apresentação dos resultados obtidos na avaliação reguladora e na avaliação final no que se refere às dimensões do domínio Reflexão

\begin{tabular}{|c|c|c|c|c|c|c|c|c|c|}
\hline \multirow{2}{*}{ DIMENSÃO } & \multirow{2}{*}{ MOMENTO } & \multirow{2}{*}{$N$} & \multirow{2}{*}{ MEDIANA } & \multirow{2}{*}{ MÉDIA } & \multirow{2}{*}{$\begin{array}{l}\text { DESVIO- } \\
\text {-PADRÃO }\end{array}$} & \multirow{2}{*}{ MíN. } & \multirow{2}{*}{ MÁX. } & \multicolumn{2}{|c|}{$\begin{array}{c}\text { TESTE DE } \\
\text { WILCOXON }\end{array}$} \\
\hline & & & & & & & & Z & $p$ \\
\hline \multirow{2}{*}{21} & 1 & 41 & 3 & 2,9 & 0,67 & 1 & 4 & \multirow{2}{*}{$-3,641$} & \multirow{2}{*}{0,000} \\
\hline & $\|$ & 41 & 3,5 & 3,4 & 0,75 & 1 & 4,5 & & \\
\hline \multirow{2}{*}{22} & 1 & 41 & 3 & 3,0 & 0,85 & 1 & 4,5 & \multirow{2}{*}{$-3,565$} & \multirow{2}{*}{0,000} \\
\hline & 11 & 41 & 3,5 & 3,5 & 0,82 & 1 & 4,5 & & \\
\hline \multirow{2}{*}{23} & 1 & 41 & 3 & 2,9 & 0,68 & 1 & 4,5 & \multirow{2}{*}{$-3,618$} & \multirow{2}{*}{0,000} \\
\hline & II & 41 & 3,5 & 3,4 & 0,79 & 1 & 4,5 & & \\
\hline \multirow{2}{*}{24} & 1 & 41 & 3 & 3,3 & 0,62 & 2 & 4,5 & \multirow{2}{*}{$-1,732$} & \multirow{2}{*}{0,083} \\
\hline & II & 41 & 4 & 3,5 & 0,75 & 1 & 4,5 & & \\
\hline \multirow{2}{*}{25} & 1 & 31 & 3 & 2,7 & 0,58 & 2 & 4 & \multirow{2}{*}{$-3,230$} & \multirow{2}{*}{0,001} \\
\hline & $\|$ & 41 & 3 & 3,3 & 0,8 & 1 & 4,5 & & \\
\hline
\end{tabular}

Fonte: Elaboração das autoras.

Momento: I - Avaliação reguladora; II - Avaliação final.

A partir da análise da Tabela 4, verifica-se, nas dimensões 24 e 25, a diminuição da avaliação mínima atribuída (desceu de 2 para 1) na avaliação final, pelo que mais uma vez procedeu-se à análise dos desempenhos individuais, permitindo constatar que novamente o aluno 8 surge como o responsável pelo registo destes valores, sendo que, na dimensão 24 , desce de 2 para 1 , e, na dimensão 25 , seu desempenho não permitiu a atribuição de uma classificação na avaliação reguladora, o qual, na avaliação final, é avaliado com 1 valor.

\section{DISCUSSÃO DOS RESULTADOS}

As análises efetuadas permitiram verificar que há diferenças estatisticamente significativas nos quatro domínios analisados entre os dois momentos de avaliação. 
No que concerne às dimensões que compõem a GAPD_PPS, as análises realizadas evidenciaram uma evolução estatisticamente significativa em 21 das 25 dimensões dos quatro domínios avaliados (Observação, Planificação, Ação e Reflexão). Mais concretamente, regista-se uma evolução do grupo de estudantes ao nível das dimensões da Observação e da Planificação. Em quatro dimensões (D13, D17, D20, D24) da GAPD_PPS, não se verificou evolução estatisticamente significativa, apesar de se ter registado, nestas dimensões, um aumento na média e na mediana quando se comparam a avaliação reguladora e a avaliação final. Três destas dimensões enquadram-se no domínio Ação (D13, D17 e D20) e a restante (D24) enquadra-se no domínio Reflexão.

Perante estes resultados, procedeu-se à análise de cada um dos itens em concreto. Assim, para D13 (organização do tempo), ainda que a diferença possa ser considerada marginalmente significativa $(p=0,054)$, sendo um domínio relacionado com a capacidade de organização e gestão do tempo, os resultados podem traduzir o facto de o grupo de estagiários, apesar da evolução que conseguiu, não ter evoluído de forma homogénea, ao mesmo ritmo e no mesmo período de tempo, condicionando assim o valor da mediana e o valor médio registados no grupo. Aliás, esta explicação parece-nos que também se poderá aplicar em relação ao D17, domínio relacionado com a integração de situações de jogo espontâneo, bem como ao D20, referente à postura democrática, ética e deontológica, e ao D24, articulação de diversos pontos de vista, valores, saberes e crenças. Em relação ao D20, acrescenta-se o facto de os alunos, na avaliação reguladora e na avaliação final, registarem os mesmos valores médios, sendo que a mediana na avaliação reguladora já se situava num valor bastante elevado, correspondendo à apreciação de muito bom+, alcançando esta, na avaliação final, o nível excelente. Nos outros três domínios, os valores da mediana são mais baixos e remetem para uma evolução grupal que se situa entre os níveis bom e muito bom. Mais especificamente, para D13, regista-se a evolução de bom para bom+; para D17, a evolução de bom+ para muito bom; e, para D24, a evolução de bom para muito bom. 
Considerando os dados apresentados, estas serão dimensões a merecer particular atenção nos processos avaliativos, para melhor compreender as tendências evolutivas observadas e a análise de casos individuais. Um dos aspetos a tomar em consideração refere-se ao diferencial grau de exigência ao nível da aprendizagem profissional destas dimensões/competências. De facto, levanta-se a hipótese de algumas destas dimensões representarem um maior desafio ao desenvolvimento profissional, designadamente no caso em análise, a D13 (organização do tempo) e a D24 (articulação de diversos pontos de vista, valores, saberes e crenças).

Detendo-nos na análise dos desempenhos individuais, foi possível verificar que 40 dos 41 participantes evidenciaram evolução positiva entre os dois momentos de avaliação. Um dos participantes (8) registou resultados mais baixos na avaliação final, comparativamente à avaliação reguladora. A análise mais específica desta situação permitiu constatar tratar-se de um estudante que não atingiu os objetivos propostos do ponto de vista do desenvolvimento de competências profissionais durante o estágio no ano letivo 2012/13, tendo realizado com sucesso o estágio no ano letivo seguinte.

Verificamos, ainda, que nas dimensões 16 (envolvimento das crianças em projetos), 18 (construção de parcerias com família e comunidade) e 25 (avalia reflexivamente o seu papel e funções considerando princípios de participação e responsabilidade social) não foram registadas respostas para todos os participantes na avaliação reguladora. Relativamente às duas primeiras dimensões, o preenchimento da dimensão não se revelava aplicável atendendo ao caso concreto do aluno e do local de estágio. Este facto sugere uma alteração à própria grelha, introduzindo-se uma coluna com a designação "não aplicável", por forma a permitir um registo mais rigoroso de circunstâncias desta natureza. Em relação à dimensão 25 , as dificuldades iniciais de interpretação do enunciado sugerem a necessidade de revisão da sua operacionalização.

Retomando o objetivo central do presente estudo, estes dados permitem retirar ilações acerca dos percursos evolutivos das/os estudantes deste ciclo de estudos, reconhecendo 
a existência de evidência acerca do desenvolvimento de conhecimentos e competências profissionais em domínios estruturantes da profissionalidade docente. Tratando-se de um processo formativo, esta evolução das/os estudantes seria expectável, fruto do conhecimento prévio das intenções formativas e da direção desejável ao nível de um percurso bem-sucedido de aprendizagem profissional. Sublinhamos, neste apartado, alguns procedimentos adotados para minorar a possibilidade de influência destes fatores, designadamente as três instâncias de avaliação utilizadas (autoavaliação; auto e heteroavaliação entre estagiárias/os e orientadora cooperante; auto e heteroavaliação entre todos os participantes implicados, estagiárias/os, orientadoras cooperantes e supervisoras/es institucionais), bem como o facto de o estudo se basear num conjunto de atribuições consensualizadas entre as/os formadoras/es e as/os estagiárias/os, o que poderá contribuir para robustecer a confiabilidade nestes dados. Refira-se, ainda, que estes procedimentos seguem práticas de qualidade internacionalmente reconhecidas ao nível da avaliação de estágios na educação infantil, nomeadamente o foco numa abordagem processual e criticamente reflexiva e a responsabilidade partilhada pelas instituições de ensino superior e de estágio, que têm vindo a caracterizar as práticas avaliativas na Itália (BALDUZZI; LAZZARI, 2015) e na Dinamarca (JENSEN, 2015).

\section{CONSIDERAÇÕES FINAIS}

Como sublinhado por Formosinho (2009), a avaliação da aprendizagem de futuros docentes faz parte da dimensão manifesta de um currículo de processos que, apesar da sua relevância, é descurada em termos de problematização. O caso particular da avaliação da aprendizagem profissional durante o estágio profissionalizante segue esta tendência, visível na escassez de estudos que a tenham reclamado enquanto objeto. De facto, e a título exemplificativo, a análise de um recente número temático da revista Early Years: An International Research Journal, dedicado à aprendizagem em contexto de trabalho e respetivas práticas de acompanhamento na 
formação de educadoras/es de infância em vários países europeus (OBERHUEMER, 2015), permitiu constatar a atenção muito marginal dada à avaliação da aprendizagem profissional no âmbito de processos de estágio na educação infantil.

O presente artigo apresenta uma proposta de avaliação da aprendizagem de competências profissionais estruturantes no que diz respeito ao perfil específico de desempenho profissional na educação infantil, em contexto português. Esta proposta parte, por um lado, da necessidade de tomar em consideração padrões de desempenho profissional validados e, por outro, de um conjunto de princípios e procedimentos que visam manter a natureza reflexiva, autêntica e participada dos processos avaliativos. Esta opção por uma avaliação autêntica, contextualizada e individualizada (DARLING-HAMMOND, 2001, 2006), envolvendo vários atores relevantes ao processo avaliativo, incluindo a/o própria/o estagiária/o (CALDERANO, 2013; CAUGHLAN; JIANG, 2014; DAYAN, 2008; WIGGINS, 1989), pretende traduzir-se em benefício para várias partes. Em primeira instância, benefícios para a/o estudante que, estando ativamente envolvida/o num processo coletivo de reflexão e deliberação, torna-se agente ativo do seu próprio processo de desenvolvimento profissional, possibilitando um afastamento de uma avaliação dirigida por lógicas burocráticas e corporativas e mais profissional (FORMOSINHO; MACHADO, 2010). De facto, é possível afirmar que o processo avaliativo é promotor de competências que ele próprio avalia, garantindo a coerência entre a teoria de aprendizagem e a teoria de avaliação preconizadas. Outro efeito positivo diz respeito ao robustecimento da confiabilidade nos processos e resultados dos processos avaliativos e investigativos, resultante de análises e deliberações participadas.

O estudo aqui relatado permitiu constatar a evolução positiva das/os estudantes deste mestrado profissionalizante em educação infantil do ponto de vista da aprendizagem profissional. Simultaneamente, e reconhecendo que a avaliação de desempenho na formação prática inicial tem vindo a ser assinalada como relevante na avaliação da qualidade dos programas de formação de docentes (DARLING-HAMMOND, 2006; WEI; PECHEONE, 2010), sublinha-se também o contributo 
deste estudo na compreensão endógena dos processos formativos. Neste caso concreto, parece-nos possível afirmar a eficácia percebida da formação realizada no âmbito deste estágio profissionalizante, reconhecendo-se a necessidade de levar a cabo uma análise das estratégias formativas que mais efeitos estarão a ter ao nível da aprendizagem profissional.

\section{REFERÊNCIAS}

ALVES, José Matias; CABRAL, Ilídia. Os demónios da avaliação: memórias de professores enquanto alunos. Estudos de Avaliação Educacional, São Paulo, v. 26, n. 63 , p. 630-662, set./dez. 2015.

BALDUZZI, Lucia; LAZZARI, Arianna. Mentoring practices in workplacebased professional preparation: a critical analysis of policy developments in the Italian context. Early Years: An International Research Journal, Abringdon, v. 35, n. 2, p. 124-138, 2015.

CALDERANO, Maria da Assunção. O estágio supervisionado para além de uma atividade curricular: avaliação e proposições. Estudos em Avaliação Educacional, São Paulo, v. 23, n. 53, p. 250-278, set./dez. 2012.

CALDERANO, Maria da Assunção. Docência compartilhada entre universidade e escola: formação inicial e continuada através do estágio curricular. São Paulo: FCC; CNPQ, 2013. Disponível em: <http://www.fcc.org.br/fcc/ images/pesquisa/estagios/projetos/MariaAssuncaoCalderano.pdf $>$. Acesso em: 21 mar. 2016.

CAUGHLAN, Samantha; JIANG, Heng. Observation and teacher quality: critical analysis of observational instruments in preservice teacher performance assessment. Journal of Teacher Education, Washington, v. 65, n. 5, p. 375-388, 2014.

DALRYMPLE, Roger; KEMP, Chris; SMITH, Patrick. Characterising work-based learning as a triadic learning endeavor. Journal of Further and Higher Education, London, v. 38, n. 1, p. 75-89, 2014.

DARLING-HAMMOND, Linda. Standard setting in teaching: changes in licensing, certification, and assessment. In: RICHARDSON, Virginia (Ed.). Handbook of research on teaching. 4. ed. Washington: American Educational Research Association, 2001. p. 751-776.

DARLING-HAMMOND, Linda. Assessing teacher education: the usefulness of multiple measures for assessing program outcomes. Journal of Teacher Education, Washington, v. 57, n. 2, p. 120-138, 2006.

DARLING-HAMMOND, Linda; NEWTON, Stephen; WEI, Ruth Chung. Developing and assessing beginning teacher effectiveness: the potential of performance assessments. Educational Assessment, Evaluation and Accountability, Berlin, v. 25, n. 3, p. 179-204, 2013. 
DARLING-HAMMOND, Linda; SNYDER, Jon. Authentic assessment of teaching in context. Teaching and Teacher Education, v. 16, p. 523-545, 2000.

DAYAN, Yael. Towards professionalism in early childhood practicum supervision: a personal journey. European Early Childhood Education Research Journal, Birmingham, v. 16, n. 2, p. 153-170, 2008.

FIELD, Andy. Discovering statistics using SPSS. 3. ed. London: Sage, 2009.

FORMOSINHO, João. A universidade e a formação de educadores de infância: potencialidades e dilemas. In: MACHADO Maria Lúcia (Org.). Encontrose desencontros em educação infantil. São Paulo: Cortez, 2002. p. 169-188.

FORMOSINHO, João. A formação prática dos professores: da prática docente na instituição de formação à prática pedagógica nas escolas. In: FORMOSINHO, João (Coord.). Formação de professores: aprendizagem profissional e acção docente. Porto: Porto, 2009. p. 93-117.

FORMOSINHO, João; MACHADO, Joaquim. Professores nas escolas de massas: novos papéis, nova profissionalidade. In: FORMOSINHO, João (Coord.). Formação de professores: aprendizagem profissional e acção docente. Porto: Porto, 2009. p. 143-164.

FORMOSINHO, João; MACHADO, Joaquim. Desempenho, mérito e desenvolvimento. Para uma avaliação mais profissional dos professores. In: FORMOSINHO, João; MACHADO, Joaquim; OLIVEIRA-FORMOSINHO, Júlia. Formação, desempenho e avaliação de professores. Mangualde: Pedago, 2010. p. 97-118.

GOMES, Marineide Oliveira. Formação de professores na educação infantil. 2. ed. São Paulo: Cortez, 2013.

JENSEN, Jytte J. Placement supervision of pedagogue students in Denmark: the role of university colleges and early childhood centres. Early Years: An International Research Journal, Abingdon, v. 35, n. 2, p. 154-167, Apr. 2015.

MARTINS, Carla. Manual de análise de dados quantitativos com recurso ao IBM SPSS. Braga: Psiquilíbrios, 2011.

MOSS, Peter; DAHLBERG, Gunilla. Beyond quality in early childhood education and care: languages of evaluation. New Zealand Journal of Teachers' Work, Auckland, v. 5, n. 1, p. 3-12, 2008.

OBERHUEMER, Pamela. Editorial - Seeking new cultures of cooperation: a cross-national analysis of workplace-based learning and mentoring practices in early years professional education/training. Early Years: An International Research Journal, Abingdon, v. 35, n. 2, p. 115-123, Apr. 2015.

OLIVEIRA-FORMOSINHO, Júlia. Modelos curriculares para a educação de infância. 3. ed. Porto: Porto, 2007.

PORTUGAL. Decreto-lei n. 241/2001, de 30 de agosto. Aprova os perfis específicos de desempenho profissional do educador de infância e do professor do $1^{\circ}$ ciclo do ensino básico. Lisboa: ME, 2001. 
PORTUGAL. Decreto-lei n. 43/2007, de 22 de fevereiro. Aprova o regime jurídico da habilitação profissional para a docência na educação pré-escolar e nos ensinos básico e secundário. Lisboa: ME, 2007.

PORTUGAL. Decreto-lei n. 79/2014, de 14 de maio. Aprova o regime jurídico da habilitação profissional para a docência na educação pré-escolar e nos ensinos básico e secundário. Lisboa: MEC, 2014.

WEI, Ruth Chung; PECHEONE, Raymond. Assessment for learning in preservice teacher education: performance-based assessments. In: KENNEDY, Mary (Ed.). Teacher assessment and the quest for teacher quality: a handbook. San Francisco: Jossey Bass, 2010. p. 60-103.

WIGGINS, Grant. A true test: toward more authentic and equitable assessment. Phi Delta Kappan, Thousand Oaks, CA, v. 70, n. 9, p. 703-713,1989.

SARA BARROS ARAÚJO

Professora-adjunta do Instituto Politécnico do Porto (IPP), Porto, Portugal

saraujo@ese.ipp.pt

ANA PEREIRA ANTUNES

Professora auxiliar da Universidade da Madeira (UMa), Funchal, Portugal

aantunes@uma.pt 
